\title{
COMPARISON OF MODEL BASED AND CLINICAL BLOOD GLUCOSE EVOLUTION DURING AND AFTER ANHEPATIC STATUS
}

\author{
Homlok, $\mathrm{J}^{1}$, Chase, $\mathrm{J} \mathrm{G}^{3}$, Turi, Cs ${ }^{1,2}$, Benyo, $\mathrm{B}^{1}$ \\ ${ }^{1}$ Department of Control Engineering and Information Technology, Budapest University of Technology and \\ Economonics, Hungary \\ ${ }^{2}$ Transplantation and Surgery, Semmelweis University, Hungary \\ ${ }^{3}$ Center for Bioengineering, University of Canterbury, New Zealand \\ homlokj@iit.bme.hu
}

\begin{abstract}
Blood glucose (BG) control is a major difficulty during liver transplantation (LT). A model-based approach to analysis and control can enhance the efficiency of $B G$ management during LT surgery. An existing clinically validated metabolic model was fitted to data from 8 LT patients. The reperfusion part of the post-anhepatic phase of $L T$ shows a clear consistent dynamic rise in blood glucose $(B G)$ level that would enable better prediction of future $B G$ in this phase. Model fitting errors showed that the fundamental model captured all primary dynamics but parameter adjustment to reflect known conditions during LT surgery in specific phases would improve model quality.
\end{abstract}

Keywords: liver transplant, blood glucose, reperfusion, metabolic model

\section{Introduction}

The liver is the primary metabolic organ in maintaining stable blood glucose (BG) levels by the storage or release of glucose from nutrition [1]. Blood glucose (BG) evolution is highly variable and difficult to control for liver transplant (LT) patients during and after surgery, particularly after reperfusion in the post-anhepatic phase [2] [3] [4]. Fig.1 shows this behaviour and how the BG level increases significantly and variably during reperfusion. However, effective BG management to moderate BG levels can enhance recovery and transplanted liver function [5].

LT surgery is thus a major metabolic challenge. BG control is severely limited, and effectively unpredictable based on normal assumptions about metabolic function. Hence, model-based analysis and control can provide improved management and outcomes.

\section{Methods}

This paper examines BG evolution in LT patients and the ability of an existing metabolic model to capture the observed dynamics. The second goal is to determine the fundamental dynamics of BG during this surgery and the reperfusion phase in particular, to define the sudden BG rise that confounds BG control.

Data: Data from 8 LT patients in the Budapest Transplantation clinic. All insulin, glucose infusion, and BG data
A

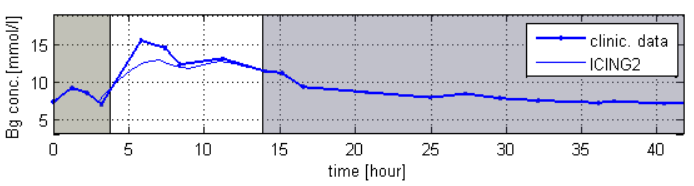

$\mathrm{B}$
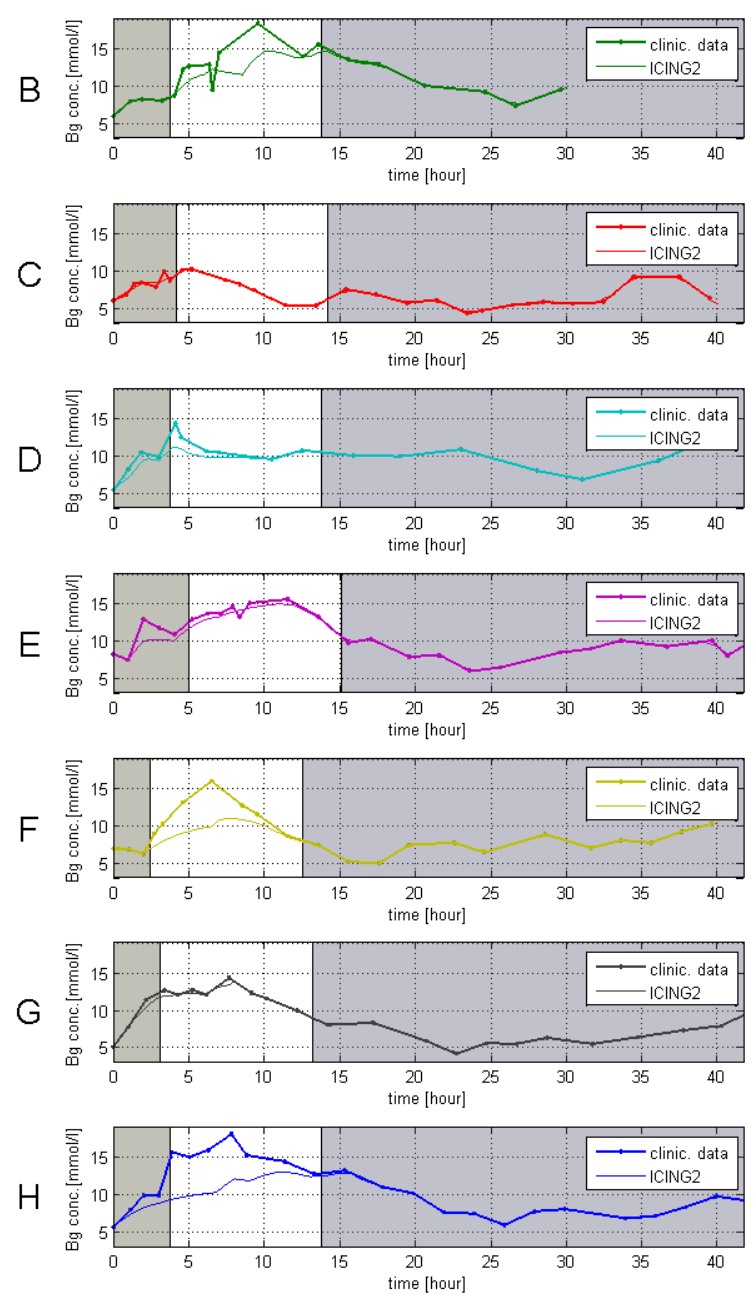

Figure 1: BG evolution for 8 LT patients (A- H). The first filled area represents the anhepatic phase until reperfusion. The second (white) section is the part of the postanhepatic phase, the clinical data show a consistent dynamic behaviour. The third (grey) section can be considered as a normalized metabolic function. 
were recorded by blood gas analyser, plus relevant clinical data on each patient. Times for each major surgical step were recorded.

ICING2 model: The ICING2 model is a clinically validated metabolic model [6]. The model is identified using the clinical data. Ability to capture observed dynamics is assessed using mean absolute percentage error (MAPE) of fitted BG values for each phase of LT surgery in Fig.1.

Reperfusion Dynamics: The second, reperfusion phase clinical data showed similar dynamics for each patient. Each BG sequence for this phase is overlaid and normalised to determine if there are a fundamental dynamic that would enable better BG control.

Table 1: Mean absolute percentage error (MAPE [\%]) of the fitting for the certain timeintervals introduced in Fig. 1

\begin{tabular}{llll}
\hline Patient & section1 & section2 & section3 \\
\hline A & 1.3532 & 6.5192 & 0.1943 \\
B & 0.6324 & 12.9562 & 0.8889 \\
C & 2.6865 & 1.0268 & 0.9930 \\
D & 8.5483 & 5.0351 & 0.1116 \\
E & 9.1447 & 3.1377 & 0.9344 \\
F & 0.8299 & 18.7366 & 0.9223 \\
G & 3.5302 & 1.5578 & 0.4648 \\
H & 11.1833 & 22.4083 & 0.7561 \\
\hline
\end{tabular}

\section{Results}

Table 1 shows the MAPE results primarily within measurement errors of $7-12 \%$ for all phases, although Patient $\mathrm{H}$ is relatively larger. There are some outliers that show additional model dynamics may need to be considered.

Fig. 2 shows the normalised reperfusion BG dynamics and an identified polynomial function. There is a clear, consistent dynamic rise in BG. The function captures this rise and can be used to improve BG prediction and control as the timeframes are exactly known.

\section{Discussion}

The model fitting errors of Table 1 indicate that the model will require some adjustment of parameters for LT patients. This result is expected because the model was defined and used for ICU patients with some measure of liver function. The LT case is quite different but the model has specific adjustable parameters.

The polynomial curve of Fig. 1 will enable better control. It captures a predictable, consistent dynamic that can be based on known surgical timing. This approach thus allows far better prediction of future behaviours and thus far better control of the BG levels to enable better recovery [5].

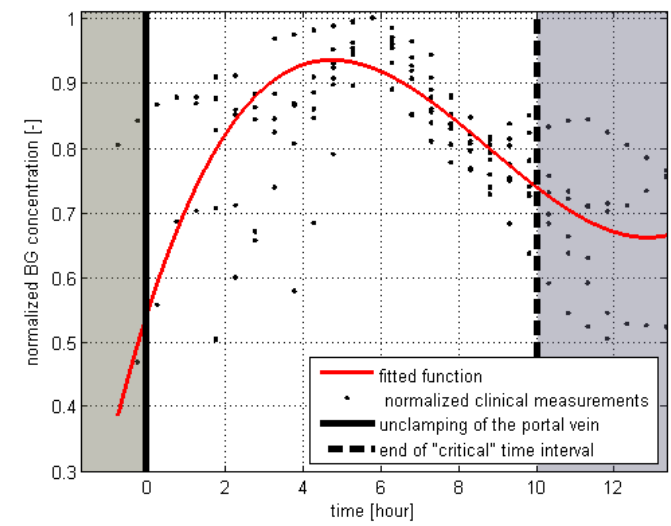

Figure 2: The second, reperfusion phase of the clinical data. The sequences are normalized and overlaid. A fitted polynomial function shows a consistent dynamic of blood glucose evolution.

\section{Acknowledgement}

This work was supported by the Hungarian National Scientific Research Foundation, Grants No. T80316 and T82066 and the EU FP7 IRSES eTime Grant No. 318943. The research work of József Homlok is supported by the Richter Scholarship.

\section{Bibliography}

[1] Gertrud Rehner and Hannerlore Daniel, "Die Leber als multifunktionelles Organ," in Biochemie der Ernährung (H. D. Gertrud Rehner, ed.), ch. 9, pp. 409487, Spektrum Akademischer Verlag Heidelberg, 2010.

[2] S. R. Atchison, S. R. Prettke, G. A. Fromme, T. A. Janossy, and S. E. Kunkel, "Plasma glucose concentration during liver transplantation," Mayo Clinic Proceedings, vol. 64, pp. 241-245, 1989.

[3] D.-Y. Kim, I. Y. Huh, Y. Woo Cho, E. Sun Park, S. Eun Park, Y. Won Nah, and C. Ryul Park, "Experience without using venoveno bypass in adult orthotopic liver transplantation," Korean J Anesthesiol, vol. 60, pp. 19-24, 2011.

[4] A. M. De Wolf, Y. G. Kang, S. Todo, I. Kam, and A. J. Francavilla, "Glucose metabolism during liver transplantation in dogs," Anesth Analg., vol. 66(1), pp. 76$80,1987$.

[5] J. B. Ammori, M. Sigakis, M. J. Englesbe, M. O'Reilly, and S. J. Pelletier, "Effect of intraoperative hyperglycemia during liver transplantation," Journal of Surgical Research, vol. 140, pp. 227-233, 2007.

[6] J. Lin, N. N. Razak, C. G. Pretty, A. J. Le Compte, P. Docherty, J. D. Parente, G. M. Shaw, C. E. Hann, and J. G. Chase, "A physiological intensive control insulinnutrition-glucose (icing) model validated in critically ill patients," Computer Methods and Programs in Biomedicine, vol. 102, pp. 192-205, 2011. 